\title{
Performance and prospects of payments for ecosystem services programs: Evidence from China
}

\author{
Wu Yang ${ }^{\mathrm{a}, *}$, Wei Liu ${ }^{\mathrm{a}}$, Andrés Viña ${ }^{\mathrm{a}}$, Junyan Luo ${ }^{\mathrm{a}}$, Guangming He ${ }^{\mathrm{a}}$, Zhiyun Ouyang ${ }^{\mathrm{b}}$, \\ Hemin Zhang ${ }^{c}$, Jianguo Liu ${ }^{\text {a,b }}$ \\ ${ }^{a}$ Center for Systems Integration and Sustainability, Michigan State University, East Lansing, MI 48823-5243, USA \\ ${ }^{\mathrm{b}}$ State Key Laboratory of Regional and Urban Ecology, Research Center for Eco-Environmental Sciences, Chinese Academy of Sciences, Beijing 100085, China

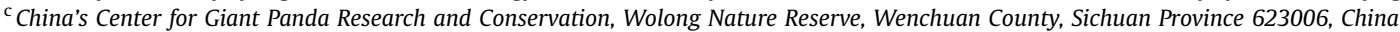

\section{A R T I C L E I N F O}

\section{Article history:}

Received 4 August 2012

Received in revised form

25 March 2013

Accepted 6 April 2013

Available online 15 May 2013

\section{Keywords:}

Community-based natural resources

management

Conservation effectiveness

Coupled human and natural systems

Incentive-based mechanisms

Natural Forest Conservation Program

Wolong Nature Reserve

\begin{abstract}
A B S T R A C T
Systematic evaluation of the environmental and socioeconomic effects of Payments for Ecosystem Services (PES) programs is crucial for guiding policy design and implementation. We evaluated the performance of the Natural Forest Conservation Program (NFCP), a national PES program of China, in the Wolong Nature Reserve for giant pandas. The environmental effects of the NFCP were evaluated through a historical trend (1965-2001) analysis of forest cover to estimate a counter-factual (i.e., without-PES) forest cover baseline for 2007. The socioeconomic effects of the NFCP were evaluated using data collected through household interviews carried out before and after NFCP implementation in 2001. Our results suggest that the NFCP was not only significantly associated with increases in forest cover, but also had both positive (e.g., labor reduction for fuelwood collection) and negative (e.g., economic losses due to crop raiding by wildlife) effects on local households. Results from this study emphasize the importance of integrating local conditions and understanding underlying mechanisms to enhance the performance of PES programs. Our findings are useful for the design and implementation of successful conservation policies not only in our study area but also in similar places around the world.
\end{abstract}

(c) 2013 Elsevier Ltd. All rights reserved.

\section{Introduction}

Much of the unprecedented degradation of important ecosystem services due to human activities (MA, 2005) has been explained using the classic 'tragedy of the commons' framework (Hardin, 1968; Jack et al., 2008). However, the landmark work by Ostrom (1990, 2009), Ostrom et al. (1999, 1994, 2007) challenged this view and suggested that common pool resources can be successfully managed even without government intervention or privatization. Nevertheless, in many cases government intervention is still necessary, particularly when local management of common pool resources does not exist or is ineffective (Jack et al., 2008). Among the different types of government intervention, payment for ecosystem services (PES) programs have recently emerged for realigning economic and social costs/benefits among different stakeholders through incentive-based mechanisms (Chen et al., 2012; Jack et al., 2008; Scherr et al., 2006). A formal definition of

\footnotetext{
* Corresponding author. Tel.: +1 517432 5068; fax: +1 5174325066 .

E-mail address: yangwu1201@gmail.com (W. Yang).
}

PES was given by Wunder (2005) as "a voluntary and conditional transaction over well-defined ecosystem services between at least one seller and one buyer".

During the past decade, hundreds of PES initiatives have emerged globally (Kalacska et al., 2008; Liu et al., 2008; Sanchez-Azofeifa et al., 2007; Wunder and Alban, 2008). Among these, China introduced two of the largest PES programs in terms of scale, total payments and duration (Liu et al., 2008; Task Force for EcoCompensation Mechanisms and Polices in China, 2007). Because in many areas participation in these programs is not completely voluntary (Yin, 2009), they may not be regarded as PES programs but rather as PES-like programs. However, for consistency, in this article we refer to them as PES programs. One of them, the Grain-to-Green Program (GTGP, also known as the Sloping Land Conversion Program or the Farm to Forest Program), was initiated in 1999 at the national level to restore natural ecosystems and to mitigate negative off-site effects (e.g., drought, flood, dust storm, sedimentation of reservoirs) caused by agricultural expansion onto marginal and/or steep land (Liu and Diamond, 2005; Liu, 2010; Liu et al., 2013). By the end of 2009, GTGP had accumulated an investment of ca. 31.7 billion USD ( 1 $\mathrm{USD}=6.3$ Chinese yuan, May 2012), with averages of 547.6 USD per 
ha and 381.0 USD per ha in the upper reaches of the Yangtze River basin and middle-upper reaches of the Yellow River basin, respectively (Liu et al., 2013). By 2009, ca. 32 million rural households enrolled ca. 8.8 million ha of cropland in the GTGP (Liu et al., 2013). The Natural Forest Conservation Program (NFCP) aims to conserve natural forests via logging bans and afforestation incentives. By the end of 2009, the NFCP had accumulated an investment of ca. 14.9 billion USD (Liu et al., 2013). To date both GTGP and NFCP have been funded entirely by the central and local governments. However, the GTGP is a direct PES program involving local households, while the NFCP is an indirect PES program that is operated by local forestry bureaus and seldom engages local households. Only in very few areas such as in Wolong Nature Reserve for giant pandas, the decentralization of NFCP implementation and engagement of local households have been attempted.

While several studies (Chen et al., 2009, 2010; Uchida et al., 2009, 2005; Viña et al., 2013; Xu et al., 2002, 2004) have evaluated the effectiveness and efficiency of the GTGP, relatively few (Xu et al., 2002; Yin, 2009) have studied the effectiveness and efficiency of the NFCP. In addition, to our knowledge no study has evaluated the decentralized implementation of the NFCP (e.g., participation of local households) and its environmental and socioeconomic consequences. Moreover, very few previous studies on PES programs throughout the world (Arriagada et al., 2009; Gross-Camp et al., 2012; Scullion et al., 2011) have addressed their environmental and socioeconomic outcomes simultaneously.

Based on more than 30 years of remotely sensed data combined with more than 10 years of household survey data, in this article we attempt to fill some of these knowledge gaps in the Wolong Nature Reserve for Giant Pandas. Our objectives are: (1) to evaluate the environmental outcomes of PES program implementation using a counter-factual without-PES baseline, estimated using the historical trend of forest cover change; (2) to capture short-term socioeconomic effects based on empirical data before and after the implementation of the PES program; and (3) to summarize effective practices and learned experiences, as well as challenges and opportunities for guiding future conservation policy design and implementation.

\section{Materials and methods}

\subsection{Study area}

We chose Wolong Nature Reserve for Giant Pandas (Ailuropoda melanoleuca) as our study area not only because it is one of the earliest nature reserves established in China, but also because it has a relatively independent administrative ability to design and implement its local PES programs. The reserve is characterized by a high biological diversity and supports approximately $10 \%$ of the total wild giant panda population (Zhang et al., 1997), making it a flagship reserve not only in China but also around the globe (Liu et al., 2003a).

The Wolong Nature Reserve (N 30 $45^{\prime}-31^{\circ} 25^{\prime}$, E $102^{\circ} 52^{\prime}-$ $103^{\circ} 24^{\prime}$, Fig. 1) is located in Wenchuan County, Sichuan Province, China, in the transition between the Sichuan Basin and the QinghaiTibet Plateau. The reserve is characterized by a high variation in topography (e.g., elevations ranging from 1200 to $6250 \mathrm{~m}$ above sea level), soils, climates and hydrological conditions (Viña et al., 2008). In 1963 (when it was first designated as a nature reserve), its size was around 20,000 ha, but was expanded in 1975 to its current size of approximately 200,000 ha (Wolong Nature Reserve, 2005). Natural vegetation in the reserve is dominated by four types of forest, all of which are associated with understory bamboo species: subtropical, evergreen broad-leaf forests ( $<1600 \mathrm{~m}$ ), evergreen and deciduous broad-leaf forests $(1600-2000 \mathrm{~m})$, mixed coniferous and deciduous broad-leaf forests (2000-2600 m), and sub-alpine coniferous forests (2600-3600 m; Schaller et al., 1985; Wolong Nature Reserve, 2005).

In 1983, the State Council authorized the reserve to establish the Wolong Special Administrative Region with the purpose of protecting regional forest ecosystems and rare plant and animal species, but primarily for the conservation of the iconic giant panda (Wolong Nature Reserve, 2005). The establishment of the Wolong Special Administrative Region allowed the reserve to be a relatively independent administrative entity. Currently, the reserve has two townships (i.e., Wolong and Gengda), with a total human population of approximately 5700, including around 4900 local residents

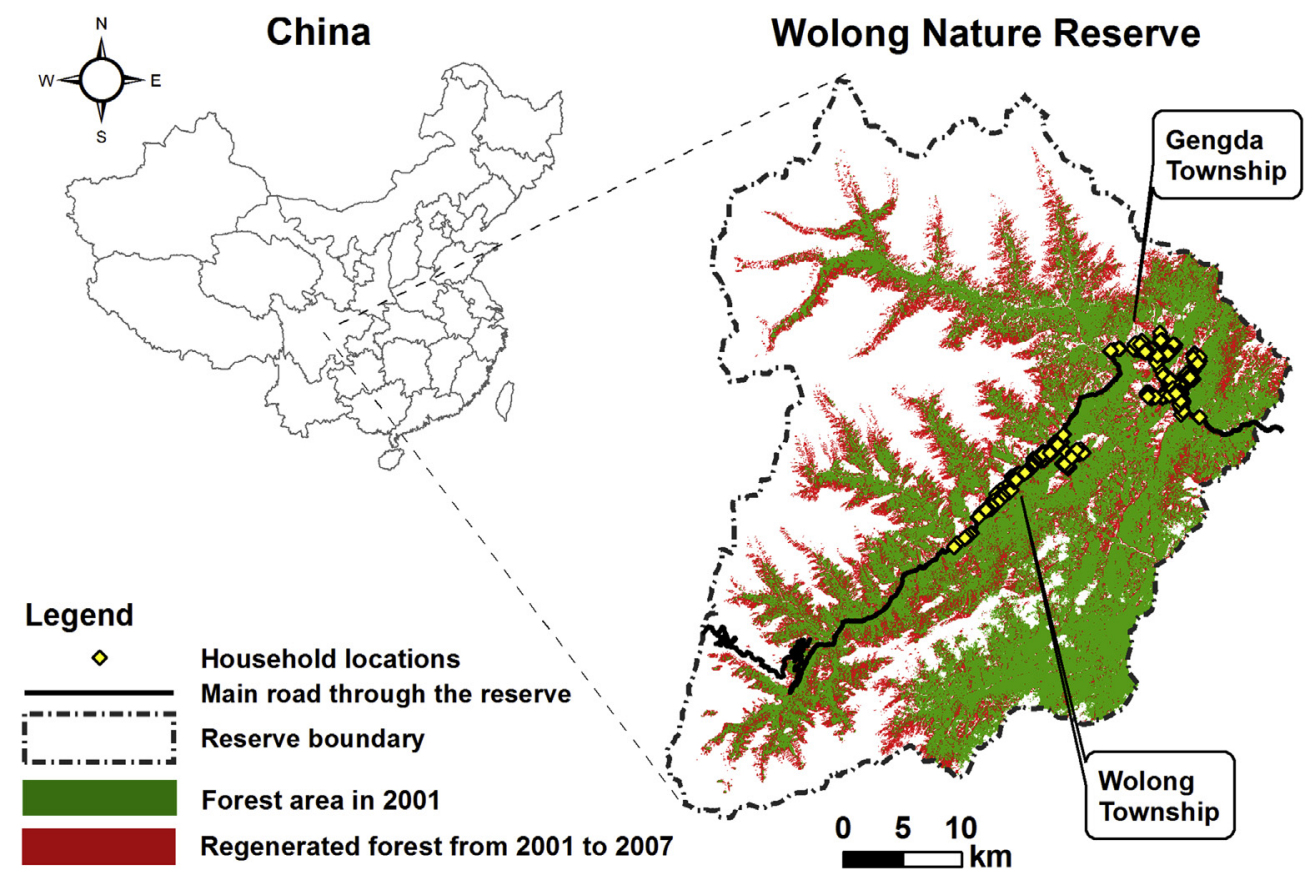

Fig. 1. Map of the Wolong Nature Reserve. (The readers are referred to the web version of the article for a version in color of this figure). 
that are distributed in approximately 1200 households. Most local residents are farmers involved in socioeconomic activities such as cultivating maize and vegetables, raising livestock, collecting medicinal plants, keeping bees, collecting fuelwood, and cooking animal and human food (Yang et al., 2013a). Fuelwood in the reserve is primarily used for heating, cooking pig fodder, cooking human food, and smoking pork. It is a local tradition to raise pigs, smoke pork using fuelwood, and eat smoked pork.

The establishment of the reserve and its expansion in 1975 did not mitigate the degradation of forest and panda habitat inside its borders (Liu et al., 2001). Therefore, several PES programs have been designed and implemented. The first one was implemented in 1986 with funds from the World Food Programme of the United Nations, through which 113 ha of cropland were converted into forest (Wolong Nature Reserve, 2005). Since 2000, two national (i.e., GTGP and NFCP) and one local (Grain-to-Bamboo Program) PES programs have been implemented in the reserve. Table 1 describes general information on these three PES programs. The three PES programs were designed to target almost all local rural households but not all households enrolled in those programs (Table 1). As opposed to other NFCP implementation areas in which afforestation practices are also included, the implementation of the NFCP in the reserve only included forest monitoring activities, targeting all the areas (approximately 120,500 ha) below the treeline (around $3600 \mathrm{~m}$ above sea level) in the reserve. As a local PES program complementing the GTGP, the Grain-to-Bamboo Program was designed to increase the bamboo cover (giant panda's main food) by enrolling cropland located within a $15 \mathrm{~m}$ buffer zone at each side of the main road (Fig. 1). The Grain-toBamboo Program has an annual payment rate of 2142.9-2857.1 USD per ha, depending on the distance to the main road and the cropland production relinquished. With comparison to GTGP, the payment rate of Grain-to-Bamboo Program is higher because it targets flatter and more productive cropland. To date, the GTGP and the Grain-to-Bamboo Program have enrolled 367.3 and 81.9 ha of cropland, respectively. But the total implemented area of GTGP and the Grain-to-Bamboo Program comprises only $0.37 \%$ of the area under the NFCP, thus direct environmental effects of these programs could be considered almost negligible. However, the GTGP and the Grain-to-Bamboo Program may induce both direct and indirect socioeconomic effects that should not be ignored (Chen et al., 2010). Therefore, we took the GTGP and Grain-to-Bamboo Program into account when specifically examining the social and economic effects of conservation policies on local households.

Besides the implementation of PES programs, the major economic development in the reserve during the past two decades has been tourism. A tourism development plan was proposed and adopted as a tool to generate funds for conservation and to provide alternative income sources for local farmers. While it started in the 1980s, this plan was not fully implemented until 2000 after the successful breeding of captive pandas and the completion of a provincial highway in the late 1990s (Liu et al., 2012). Thus, while only $4 \%$ of the households in the reserve participated in tourism activities in 1998, this increased to $28 \%$ in 2007 (Liu et al., 2012). Tourism development has grown in tandem with infrastructure development (e.g., road, hotels, and hospitals) and with government revenue. However, more than $96 \%$ of the total tourism revenue has been retained by the local government and an outside tourism company, limiting the benefits to local households (He et al., 2008; Liu et al., 2012).

\subsection{Forest cover dynamics}

The dynamics of forest cover in the reserve were obtained from forest cover maps developed in previous studies (Liu et al., 2001; Viña et al., 2007, 2011). These maps were developed using data from different satellite platforms (i.e., Corona, Landsat MSS and Landsat TM) combined with ground-truth data acquired during field work. These maps depict information on forest cover in the reserve during the years 1965, 1974, 1987, 1994, 1997, 2001 and 2007. Image classification procedures ranged from visual interpretation (Liu et al., 2001) to unsupervised digital image classification (Viña et al., 2007, 2011) using the ISODATA technique, an iterative process for non-hierarchical pixel classification (Jensen, 1996). Overall accuracies of these maps were between $78 \%$ and $88 \%$ using independent ground-truth data (Liu et al., 2001; Viña et al., 2007, 2011). These maps included two main land cover classes (i.e., forest and non-forest). For a detailed description of classification procedures and assessments of map accuracy please refer to the cited studies (Liu et al., 2001; Viña et al., 2007, 2011).

\subsection{Focus group, individual and household interviews}

To understand planning, implementation, evaluation and decision making processes involved with the NFCP, we conducted focus group, individual, and household interviews. We invited eight staff members of the reserve for focus group interviews in 2002, 2007, 2009 and 2010. These people were selected because they were directly participating in the implementation and evaluation processes of the NFCP. These focus group interviews were organized to discuss forest monitoring activities before the NFCP, perception toward NFCP benefits and costs, and problems and challenges

Table 1

General information about the PES programs in Wolong Nature Reserve.

\begin{tabular}{|c|c|c|c|}
\hline Item & Natural Forest Conservation Program (NFCP) & Grain-to-Green Program (GTGP) & Grain-to-Bamboo Program \\
\hline Beginning date & 2001 & 2000 & 2002 \\
\hline Duration & $\begin{array}{l}10 \text { years (renewed in } 2010 \\
\text { for another } 10 \text { years till 2020) }\end{array}$ & 8 years (renewed in 2008 for another 8 years) & 8 years (ended in 2010) \\
\hline Legal mechanism & National conservation policy & National conservation policy & $\begin{array}{l}\text { Local conservation policy } \\
\text { complementing the GTGP }\end{array}$ \\
\hline Targeted area & $\begin{array}{l}\text { Forest parcels near household } \\
\text { locations along the main road }\end{array}$ & $\begin{array}{l}\text { Cropland with slopes larger than } 25^{\circ} \text {, } \\
\text { which are around household locations }\end{array}$ & $\begin{array}{l}\text { Cropland within the } 15 \mathrm{~m} \text { buffer zone } \\
\text { at each side of the main road }\end{array}$ \\
\hline Targeted households & 1130 rural households $^{\mathrm{b}}$ & All 1200 rural households & All 1200 rural households \\
\hline Implemented area & $\begin{array}{l}\text { All land below treeline (i.e., } 120,500 \text { ha } \\
\text { and } 3600 \mathrm{~m} \text { above sea level), of which } \\
40,100 \text { ha were assigned } \\
\text { for household monitoring }\end{array}$ & 367.3 ha from 969 households & 81.9 ha from $\sim 530$ households \\
\hline Average payment rate ${ }^{a}$ & $\sim 143$ USD per household per year & $\sim 571$ USD per ha per year & 2143-2857 USD per ha per year \\
\hline
\end{tabular}

${ }^{\text {a }}$ Household interviews, 1 USD $=6.3$ Chinese yuan as of May 2012.

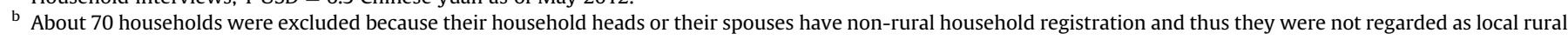
households. Source: Wolong Administrative Bureau. 
during the NFCP implementation. We also had individual discussions with five officials who were in charge of NFCP planning, implementation, evaluation and decision making in 2002, 2007, 2009 and 2010. The information obtained from focus and individual interviews were further verified from published and unpublished governmental documents as well as through household interviews.

For household interviews, we usually chose the household heads or their spouses as interviewees because they are the decision makers and are familiar with household affairs (An et al., 2001). For the household interview before the NFCP, we used data acquired in 1999 (220 households through stratified random sampling, approximately $20 \%$ of the total households in the reserve) from previous studies (An et al., 2002, 2003) by our research team. Data after the implementation of NFCP were acquired in 2002 (200 households), 2007 (192 households) and 2009 (207 households). About 170 randomly sampled households were always surveyed across the different years (i.e., panel data). The panel surveys elicited basic information such as demographic status, household socioeconomic activities (i.e., income and expenditure) and energy use (e.g., fuelwood and electricity). In the 2007 and 2009 surveys, besides basic information from panel surveys, we also added questions regarding NFCP, GTGP and Grain-toBamboo Program payments, and perceptions toward NFCP implementation. All monetary measures used in analyses were discounted into constant values in the year 2007.

\subsection{Local adaptation and implementation of the NFCP}

Like in Costa Rica (Sanchez-Azofeifa et al., 2007), a national PES implementation authority exists for the NFCP in China. The annual budget for NFCP implementation in the reserve was 389,206 USD, of which 380,000 USD and 9206 USD were from the central and provincial governments, respectively. With assistance from the Forest Inventory and Planning Institute of Sichuan Province (Fig. 2), the Wolong Administrative Bureau designed and implemented a local NFCP. On the one hand, the administrative bureau intended to reduce conflicts with local households on forest use and engage them in forest monitoring activities through economic incentives (i.e., payments). On the other hand, the administrative bureau hoped that the NFCP payment would compensate the foregone household income sources, reduce illegal logging and fuelwood collection, and even increase household income by encouraging

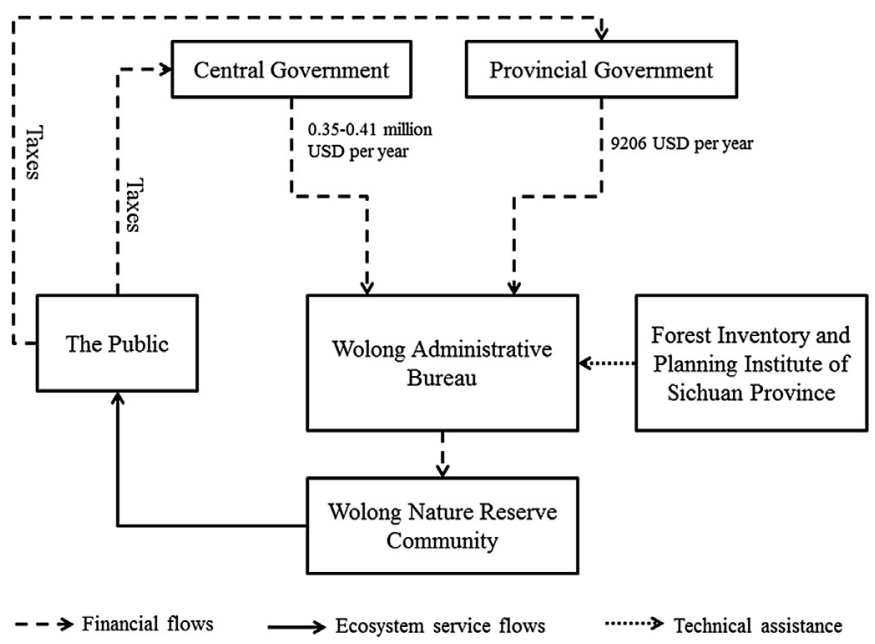

Fig. 2. Natural Forest Conservation Program (NFCP) implementation in the Wolong Nature Reserve (WNR). households to switch from on-farm to off-farm economic activities. The NFCP payment rate for each household was fixed across years and was decided based on available funding from central and provincial governments, excluding administrative and operational costs (e.g., costs for government patrolling and biannual NFCP evaluations). The administrative bureau also hoped that the switch from fuelwood to electricity would reduce the pressure on forests. Before the implementation of NFCP, there were eight small hydropower stations in the reserve with a total capacity of $34 \mathrm{MW}$ (Wolong Nature Reserve, 2005). But the electricity generated from these hydropower stations was mostly exported outside the reserve. To assist the implementation of NFCP and promote the switch from fuelwood to electricity, local power grids were upgraded and a so-called ecological hydropower station with a total capacity of $1600 \mathrm{~kW}$ was constructed in 2002. This ecological hydropower station compensated the electricity price for local households by 0.01 USD per $\mathrm{kW}$-h, leading to an actual unit residential electricity price of 0.03 USD per $\mathrm{kW}-\mathrm{h}$ (Wolong Nature Reserve, 2005). Finally, an integrated local program of NFCP was implemented, which included the logging ban, payments for household participatory forest monitoring activities, upgrading of rural power grids, compensation for electricity price, and the establishment of forestry police force to enhance policy enforcement.

Approximately 40,100-ha forest (about one third of the total implementation area in the reserve) was assigned to around 1130 households, with an annual average payment rate of approximately 143 USD per household (Table 1), while the remaining area was monitored by the staff of the Wolong Administrative Bureau. Initially, the Wolong Administrative Bureau attempted to assign a single forest parcel to each household. However, this approach turned out to be very difficult to implement because of the difficulty in clarifying forest parcel boundaries. Therefore, the Bureau finally decided to assign large forest parcels, defined using natural boundaries (e.g., rivers, ridges, valleys), to groups ranging in size from 1 to 16 households (Yang et al., 2013c). Of the 40,100 ha of forest assigned to household monitoring activities, around 16,700 ha were assigned to individual households while the remaining areas were assigned to groups with two or more households. Through this approach, a household-group monitoring approach was created which binds households together for forest monitoring activities. Each household in a group shared the same monitoring responsibility and received the same amount of payment as other household members. The Bureau evaluates the performance of household forest monitoring activities through biannual field assessments of illegal activities (e.g., logging, hunting, mining, grazing in restricted areas, collection of seeds and bamboo shoots, and other activities considered to negatively affect soils, wildlife and natural vegetation) using a score-based quantitative evaluation standard for deducting payments. All local residents are encouraged to report illegal activities and will be rewarded in cash by the Bureau. If any illegal activity is detected in a forest parcel, all households in its corresponding group will have the same amount of payment deduction, unless they identify the culprits of the illegal activity to the Bureau (Yang et al., 2013c).

\subsection{Baseline for environmental benefits}

A fundamental question of any PES program is its ability to address "additionality" (i.e., difference in ecosystem services provision between the with-PES scenario and a without-PES baseline). In other words, is the additionality sufficiently large to warrant implementation of a particular PES program (Wunder, 2007)? To answer this question it is necessary to first identify a counterfactual without-PES baseline scenario. Such counter-factual 
scenario may take any of three forms: static, deteriorating, or improving (Wunder, 2007), which are difficult to identify if the PES program is already operational. However, it can be approximated using historical trends involving time periods before PES program implementation, analyzing changes in similar without-PES study areas (e.g., adjacent sites) or analyzing changes in larger regions or administrative entities such as using entire countries as a baseline for local PES program implementations (Kalacska et al., 2008). In this study we chose to analyze the historical trend of forest covers from 1965 to 2001 in the reserve to estimate the without-PES baseline in 2007. This is a common approach used by the REDD and REDD+ (Reducing Emissions from Deforestation and forest Degradation, conservation, sustainable forest management and enhancement of forest carbon stocks) program (FONAFIFO et al., 2012; Olander et al., 2008). We chose this approach for two main reasons. First, because NFCP is a national conservation policy, it was impossible to select appropriate without-PES baseline from similar study sites or use larger regional or administrative entities (e.g., entire China). Second, before the local implementation of NFCP in 2001, forest dynamics in the reserve showed a deteriorating trend from 1965 to 2001 (Liu et al., 2001; Viña et al., 2007) while China overall had been experiencing forest gains since the middle of 1980s (State Forestry Administration of China, 2005). In addition, we acknowledge that the rapid socioeconomic development since the 1990s would also contribute to reduce the pressure on forests. But it should be noted also that external impacts (e.g., socioeconomic development) on the reserve had existed since 1961, particularly with the construction of unpaved roads and had become more intensive since 1992 with the construction of paved roads (Wolong Nature Reserve, 2005). Thus, the historical trend in forest cover already included part of these macro-socioeconomic impacts.

Other synchronous factors such as the GTGP implementation and tourism development may have interaction effects with NFCP on forest cover change. However, the GTGP only accounts for a very small percentage $(<1 \%)$ of the total land area of the reserve (Wolong Nature Reserve, 2005) and few local households have directly participated in, and benefited from, tourism related activities (He et al., 2008; Liu et al., 2012). Therefore, these factors were not likely to be a major driving force of land cover change in the reserve. Moreover, the main activities responsible for deforestation in the reserve (i.e., logging and fuelwood collection) have been reduced due to the implementation of NFCP (see Section 3.2 below). Our previous studies (Tuanmu, 2012; Viña et al., 2011; Yang et al., 2013c) also suggest that the NFCP has been a major driving force of forest change in the reserve and surrounding areas since 2001. Viña et al. (2011) indicated that NFCP together with GTGP led to the forest transition in Wenchuan County, from a net forest loss in 1990s to a net forest increase from 2001 to 2007. Tuanmu (2012) suggested that controlling for other confounding factors different NFCP monitoring approaches and payment rates in different areas caused different change rates of panda habitat (of which forest is an essential component) across space. Yang et al. (2013c) showed that different NFCP monitoring efforts of household groups led to varied changes in forest cover. Therefore, using the historical forest trend from 1965 to 2001 to estimate the forest area in 2007 as a without-PES baseline constitutes a reasonable approximation for evaluating the additionality of the NFCP implementation. However, as the reserve adopted the integrated NFCP implementation approach, the NFCP additionality evaluated should be attributed not only to the NFCP but also to other auxiliary measures (i.e., logging ban, upgrading of rural power grids, compensation for electricity price, and the establishment of forestry police force to enhance policy enforcement).

\section{Results}

\subsection{Environmental effects of the NFCP implementation in Wolong Nature Reserve}

Implementation of the NFCP seems to have reduced illegal logging and increased forest cover in the reserve (Figs. 3 and 4a). All stakeholders in the focus group, individual and household interviews shared the opinion that illegal logging activities were reduced largely in response to the NFCP.

The equation of historical forest trend from 1965 to 2001 for linear extrapolation of without-PES baseline in 2007 is given as

$Y=-857.74 X+1.79 E-6 \quad R^{2}=0.94$

where $Y$ is the area of forest cover (ha), and $X$ is year.

An increase in forest cover is evident post-NFCP implementation. The with-PES forest cover in 2007 was significantly higher than the estimated without-PES forest cover in $2001(p<0.05$, Fig. 3). Before NFCP implementation, total forest cover decreased from approximately 106,000 ha in 1965 to around 70,000 ha in 2001, while it recovered to approximately 79,000 ha in 2007. Based on forest cover dynamics between 1965 and 2001, the estimated without-PES baseline for 2007 was approximately 68,000 ha. Therefore, the additionality of the PES program between 2001 and 2007 might be estimated as around 11,000 ha, which accounts for roughly $5.5 \%$ of the total land area in the reserve.

Due to the differences in accuracy of land cover maps and other synchronous interaction effects (e.g., effects of GTGP, tourism development), the approximately 11,000 ha gain in forest cover cannot be completely attributed to the NFCP. However, it constitutes a reasonable estimation of the additionality, particularly because of the lack of other major drivers of land cover change and of the observed transition from forest loss before NFCP to forest gain after NFCP implementation (See Section 2.5). From 2001 to 2007, the cumulative financial NFCP investment in the reserve by the central and provincial governments was 2.8 million USD (Wolong Nature Reserve, 2005). Considering only this direct investment and excluding indirect investments (e.g., tourism development, donations to conservation), the cost-effectiveness ratio might be estimated as around 254.5 USD per ha of forest gained.

\subsection{Socioeconomic effects of NFCP implementation in Wolong Nature Reserve}

The implementation of the NFCP may be triggering not only environmental but also socioeconomic effects. While many effects

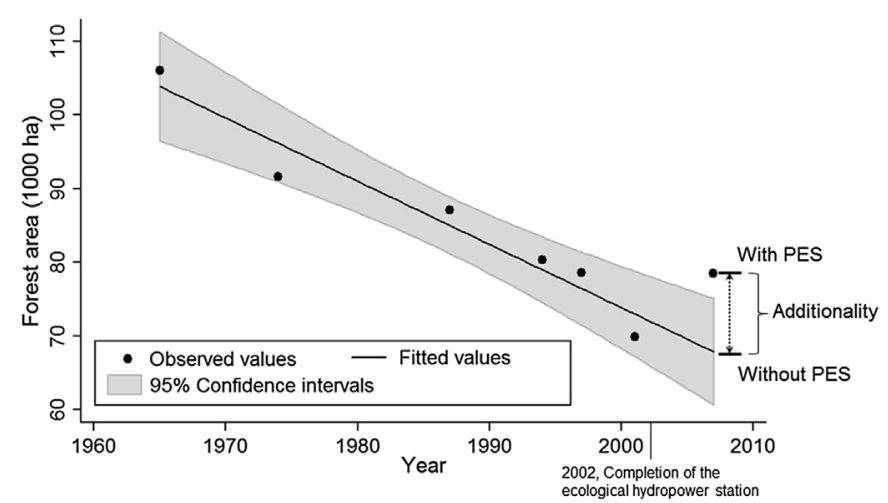

Fig. 3. Forest cover area before and after the Natural Forest Conservation Program (NFCP) implementation in 2001. The historical forest cover trend from 1965 to 2001 was used to estimate the counter-factual without-PES baseline in 2007. Additionality is the difference between the with-PES outcome and the without-PES baseline. 


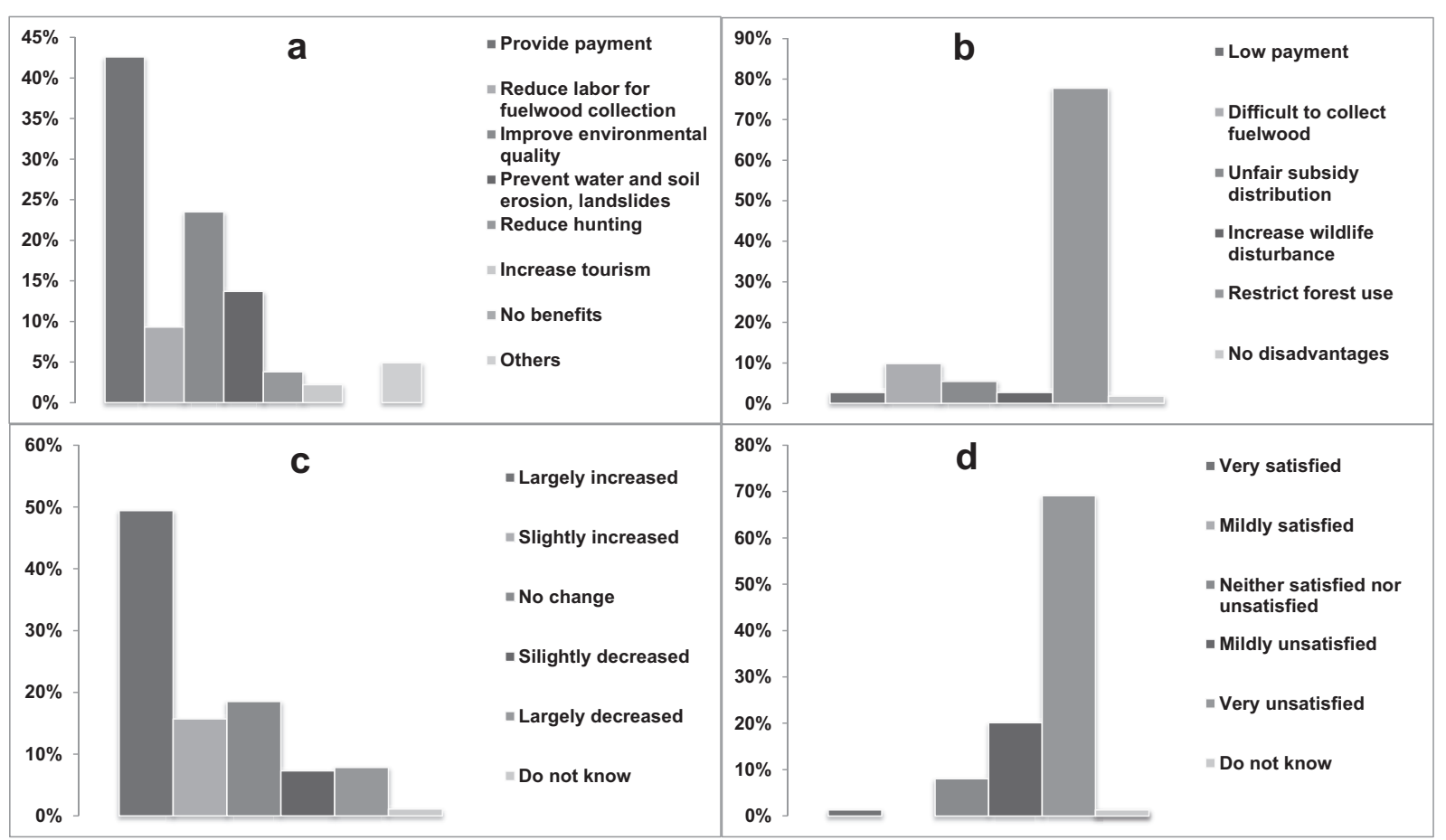

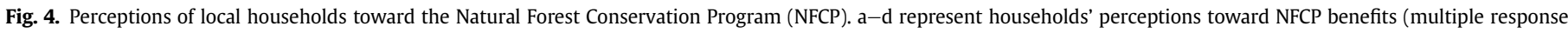

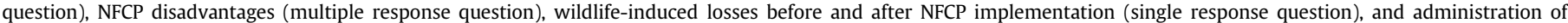
wildlife-induced losses (single response question), respectively. The total number of observations for each figure panel was 183.

may not be measurable in the short term, some short-term effects are conspicuous and could be associated with the NFCP implementation. For instance, a shift in the use of different energy sources (i.e., from fuelwood to electricity) was conspicuous shortly after NFCP implementation. The amount of electricity consumption per household doubled, while the amount of labor force spent in collecting fuelwood almost halved after NFCP implementation (Table 2). In addition, the energy source for cooking and heating shifted significantly from high reliance on fuelwood to electricity, while the number of months using fuelwood for cooking pig fodder also decreased. Given that the energy use shift from fuelwood to electricity occurred shortly after NFCP implementation but before

Table 2

Paired $t$-test for indicators of energy use before and after the NFCP implementation.

\begin{tabular}{cccc}
\hline & $\begin{array}{l}\text { Pre-NFCP } \\
\text { (Mean } \pm \text { S.D.) }\end{array}$ & $\begin{array}{l}\text { Post-NFCP } \\
\text { (Mean } \pm \text { S.D.) }\end{array}$ & $\begin{array}{c}\text { Paired } t \text {-test } \\
\text { (two-tailed) }\end{array}$ \\
\hline $\begin{array}{c}\text { Electricity consumption } \\
\text { amount (kW-h, } N=169)\end{array}$ & $1165 \pm 1301$ & $2562 \pm 1906$ & $-9.57^{* * *}$ \\
$\begin{array}{c}\text { The amount of labor force } \\
\text { for fuelwood collection } \\
\text { per year (laborer days, } \\
N=151)\end{array}$ & $64 \pm 30$ & $33 \pm 29$ & $10.02^{* * *}$ \\
$\begin{array}{c}\text { Duration of cooking pig } \\
\text { fodder with fuelwood } \\
\quad \text { months, } N=149)\end{array}$ & $11.8 \pm 1.4$ & $10.2 \pm 3.4$ & $6.09^{* * *}$ \\
$\begin{array}{c}\text { Energy source for heating } \\
\quad(N=148)\end{array}$ & $4.9 \pm 0.4$ & $3.7 \pm 1.6$ & $8.70^{* * *}$ \\
$\begin{array}{c}\text { Energy source for cooking } \\
\text { human food }(N=149)\end{array}$ & $4.5 \pm 0.9$ & $2.3 \pm 1.4$ & $19.10^{* * *}$ \\
\hline
\end{tabular}

Notes: ${ }^{*} p<0.05,{ }^{* *} p<0.01,{ }^{* * *} p<0.001$.

Pre-NFCP and post-NFCP refer to the year 1998 (i.e., reference year before NFCP) and 2001 (i.e., the first year after NFCP implementation), respectively.

Energy source was classified into a 5-score scale on percentage of fuelwood use, with 1 for no use of fuelwood, 2 for $25 \%$ of fuelwood, 3 for $50 \%$ of fuelwood, 4 for $75 \%$ of fuelwood, and 5 of $100 \%$ use of fuelwood, respectively. the upgrading of rural power grids and the completion of the ecological hydropower station, this shift was most likely caused by other measures (i.e., the logging ban and payments for forest monitoring) in the integrated NFCP implementation approach. Finally, no significant relation between household income and labor force spent in fuelwood collection was found (Pearson's $r=0.783, p>0.1$ ). Combined, these results suggest a general pattern of switching from fuelwood to electricity irrespective of household economic status.

On average, total household income doubled from 1998 to 2001 and quadrupled from 1998 to 2007. Most (i.e., 89\%, $N=183$ ) interviewed households reported that the NFCP had brought more benefits than costs to them. Overall household perception is that the implementation of NFCP provided payment, improved environmental quality, prevented water and soil erosion, landslides, and promoted tourism development (Fig. 4a). However, negative effects brought by the NFCP implementation were also reported. The most reported issue was the restriction on forest use (Fig. $4 \mathrm{~b}$ ). Interviewees claimed that their ancestors lived in the region for hundreds of years before the establishment of the reserve. For several generations they have depended on forest resources (e.g., timber, wildlife for hunting, fuelwood, traditional Chinese medicinal herbs, mushrooms, bamboo shoots, and other non-timber forest products). The NFCP implementation has inhibited many of these activities, and thus cultural traditions and customs (e.g., using fuelwood to cook pig fodder, smoking pork with fuelwood, and eating smoked pork) have been affected. Other complaints include the difficulty to collect fuelwood, as $80 \%$ of the 183 interviewees reported that they had to search a larger area to collect fuelwood due to the logging ban established by the NFCP (Fig. 4b). Almost all households incurred wildlife-induced losses with different damage rates, although not all of them attributed such losses to the NFCP implementation. Approximately $65 \%$ of the 183 interviewees claimed that wildlife-induced losses (e.g., loss of crops and livestock due to wildlife predators such as wild boars, 
hog badgers, bears, and monkeys) have significantly increased after the NFCP implementation (Fig. 4c). Approximately 89\% of the 183 interviewees were unsatisfied or very unsatisfied with government inaction (i.e., no measures to reduce wildlife-induced losses or no compensation for wildlife-induced losses) (Fig. 4d).

\section{Discussion}

Before the NFCP implementation, the reserve suffered ecological degradation in the form of deforestation and giant panda habitat losses (Liu et al., 2001). Unlike many other areas in China, the implementation of NFCP in the reserve engaged various stakeholders and developed a local program that integrates a logging ban with payments for monitoring activities and included multiple auxiliary measures (i.e., upgrading of rural power grids, compensation for electricity price, and the establishment of forestry police force to enhance policy enforcement). Environmental and socioeconomic outcomes of the NFCP implementation were mixed, having both positive and negative outcomes.

While an increase in forest cover was observed in association with the implementation of the NFCP, it should be mentioned that little information is currently available for the entire reserve on the species composition of these areas of forest gain. Field observations have shown that some of these areas seem to be dominated by exotic and potentially invasive fast-growing species (e.g., Japanese larch, Larix kaempferi). However, previous studies have shown that giant pandas and other native wildlife species including the Asiatic black bear (Ursus thibetanus) used some of these areas (Bearer et al., 2008), suggesting that secondary forests may also provide habitat for wildlife species and thus facilitate biodiversity conservation. In addition, the overall giant panda habitat suitability has increased, particularly in NFCP implementation areas (Tuanmu, 2012), suggesting that some of the forest areas restored have in fact become suitable habitat for the pandas. Therefore, while the environmental benefits obtained from the increase in forest cover associated with the NFCP seem to be spatially heterogeneous, overall they seem to be positive, at least in terms of habitat restoration for some wildlife species.

The effects of different conservation and development policies on changes in total household income were also mixed. Results from econometric models developed by our research group (Yang et al., submitted for publication) suggest that GTGP and Grain-toBamboo Program payments, initial electricity subsidy, and tourism participation had positive effects on changes in total household income from 1998 to 2007, respectively. With all other variables controlled at their average values, a $1 \%$ increase of total GTGP and Grain-to-Bamboo Program payments, or a $1 \%$ increase of initial electricity subsidy would on average increase the total household income by $2 \%$ and $0.04 \%$, respectively. Ceteris paribus, households participating in tourism activities on average had a $54 \%$ higher increase of total household income than those that did not participate. However, only less than $28 \%$ of the households participated either directly or indirectly in tourism activities. Meanwhile, NFCP payment did not have a significant effect on changes in total household income from 1998 to 2007 ( $p>0.1$ ), while the interaction term between NFCP payment and tourism participation had a negative effect $(p<0.05)$. The drastic increase in total household income from 1998 to 2007 was largely due to selling agricultural products (e.g., cabbages) outside the reserve, conducting local or migrant labor, and participating in tourism (Liu et al., 2012; Yang et al., 2013a).

Below we summarize some of the lessons learned through the NFCP implementation in the reserve, as well as some challenges and opportunities.

\subsection{Lessons learned through NFCP implementation in Wolong Nature Reserve}

Several reasons were given by the interviewed households for the significant reduction in forest cover losses (multiple response question), among which decentralization of monitoring activities to households (44\% of 174 respondents) and payment for forest monitoring activities (40\% of 174 respondents) were ranked as the two most important. Other reasons, such as the upgrading of rural power grids and subsidies on electricity, were also highlighted as important in reducing forest cover losses. The introduction of the forest police team for enhancing NFCP enforcement was also regarded as an important contributor to the reduction in forest cover losses. Such vigorous local enforcement has also been shown effective in other PES programs in Ecuador (Wunder and Alban, 2008) and in several other places around the world (Chhatre and Agrawal, 2008). Vigorous local enforcement efforts together with decentralization of monitoring activities stimulate greater participation and cooperation of service providers by curtailing expected returns from alternative illegal forest uses, hence rendering participation in PES programs more attractive (Chhatre and Agrawal, 2008).

The decentralization of forest monitoring to households complemented previous command-and-control measures. This decentralization encouraged the participation in, and compliance with, forest conservation policies. A previous study by our research group has found that panda habitat (for which forest cover is essential), recovered faster in household monitored parcels than in government monitored parcels, after controlling for other contextual factors (e.g., elevation, slope, aspect, distance to the main road) (Tuanmu, 2012). We have also found that the effects of group size (i.e., the number of households for monitoring a forest parcel) on household monitoring efforts and forest outcomes are nonlinear, with intermediate group size (i.e., 9 in a range from 1 to 16 households) performing the best (Yang et al., 2013c). The optimum group size also shifts with context. These results confirm the point of no 'panacea' or no 'one-size-fit-all' approach for successful management of common pool resources (Ostrom, 1990, 2009; Ostrom et al., 1999, 1994, 2007), and explain why the practice of household-group monitoring in the reserve turned out to be quite effective. On the one hand, with smaller group sizes, households tend to free ride (i.e., do not participate in forest monitoring activities), particularly if there are inadequate punishment measures within the group. On the other hand, as group size increases, a household would face increasing pressure of deteriorating social relationships with other households in the group, and thus would be less likely to free ride (Yang et al., 2013c). Our previous study (Yang et al., 2013c) confirmed these two opposing effects of group size and the balance between them led to the observed nonlinear response. However, such mechanisms were not considered by the corresponding policy makers during the initial NFCP design process. The decentralization and group size formation, although successful, were more random than planned. Therefore, for guiding future policy design and implementation it is essential to first consider the mechanisms underlying the potential success or failure of particular policy prescriptions.

The synchronous reduction of fuelwood consumption, increase of electricity consumption, and decrease of labor force for fuelwood collection activities shortly after the NFCP implementation and before the upgrading of rural power grids and the completion of the ecological hydropower station suggest that the logging ban and payments for forest monitoring were the most likely candidates in reducing the pressure on forests. Later, upgrading rural power grids and the ecological hydropower station may have also contributed to the reduction of logging and forest recovery. Such an upgrade 
combined with subsidies for electricity use provided an alternative energy source that simplified the switch from fuelwood to electricity. This suggests that auxiliary measures offering alternative livelihoods are essential for the successful implementation of PES programs. Rather than relying on command-and-control measures, service buyers should then guide and facilitate service providers to change environmentally harmful behaviors with alternative solutions.

The integration of quantitative evaluation standards with the PES incentive and punishment mechanism served as a rigorous and sinewy gate guard for policy enforcement. The essential difference between this evaluation approach and previous approaches was the emphasis on performance-based measures complementing with command-and-control measures. This specifically involved the design and execution of an evaluation criterion aimed at assessing the outcomes of the NFCP implementation rather than the processes or procedures for household forest monitoring. Meanwhile, all the outcomes were linked with the incentive and punishment mechanisms (i.e., PES distribution and relevant law enforcement). Without this integrated evaluation approach, the motivation for regular voluntary forest monitoring by households may largely diminish, as penalties would not be effectively executed. Without this performance-based evaluation measures the PES program may have been ineffective.

\subsection{Challenges and opportunities}

The overall environmental and socioeconomic performances of the NFCP in the reserve were mixed and there were still some unresolved questions. For instance, could the PES program be more effective or efficient? Was it ethical to achieve conservation goals with the socioeconomic costs on local communities? Here we argue that the PES program could be conducted in a more effective, efficient, ethical and sustainable manner.

First, fundamental questions on PES are, to whom, and how much should be paid? From an efficiency perspective, only those who constitute a credible threat to ecosystem services provision should be in the scope of a PES program (Wunder, 2005). But if this is the case, this perspective may be unfair to those who do not threaten ecosystem service provision. However, those who do not threaten the provision of ecosystem services usually do not have opportunity costs from foregone environmentally harmful activities (e.g., logging) and may even obtain benefits due to the externality of ecosystem service provision. As pointed out by Wunder (2005), "the ideal ecosystem service seller is, if not outright environmental nasty, then at least potentially about to become so". The current NFCP payment rate in the reserve was designed in the year 2001 as a flat payment, which is becoming less attractive because of inflation and increasing opportunity costs. Thus, ideally those who do not or potentially will not be involved in any threatening deforestation activities should not be included in the NFCP. Even with a fixed budget, savings from the reduction of participants may be used to appropriately increase payment rates, to make them more attractive and competitive. However, it is necessary to first develop strategies for targeting an optimal pool of participant households, while keeping the selection of participants voluntary, objective, and transparent. Theoretically, such targeting strategies and payment levels should be jointly designed to maximize environmental benefits with a given budget (Alix-Garcia et al., 2008; Wunscher et al., 2008). Lessons and experience on designing targeting strategies (e.g., inverse auction systems) and payment programs (e.g., discriminative payment levels) may be learned from studies not only in this region (Chen et al., 2010; Viña et al., 2013) but also from other regions (Alix-Garcia et al., 2008; Uchida et al., 2005; Wunscher et al., 2008).
Second, diversified funding would be critical for sustainable management of the PES program. Theoretically, there are five basic types of service buyers, who respond to different motivations (Scherr et al., 2006), including: (1) philanthropic buyers motivated by nonuse values; (2) public sector buyers (e.g., governmental administrations at different scales); (3) private businesses, organizations or communities who engage in private deals to secure use values or other business benefits; (4) private buyers who are under regulatory obligation to offset environmental impacts, and (5) consumers of ecocertified products and services. The current NFCP implementation is dominated by the form of public sector buyers (i.e., government compensation mechanism), which currently exhibit the greatest expectations for many sectors in China (Task Force for EcoCompensation Mechanisms and Polices in China, 2007). However, as it is widely accepted, government compensation mechanisms have limitations that are difficult to overcome, including the lack of elasticity, difficulty in defining payment rates, high operational costs, and excessive governmental fiscal pressure, among others (Liu et al., 2008; Task Force for Eco-Compensation Mechanisms and Polices in China, 2007). Currently, except through PES programs, many nonmarket ecosystem services (e.g., water purification, carbon sequestration) are being consumed but are not being paid for (Jack et al., 2008; Yang et al., 2008). Thus, to secure financial sustainability of current and future PES programs, both public and private funds should be engaged. In the reserve, for example, hydropower companies in the basin provide a small compensation amount for the electricity they produce but they should provide more funds since they directly benefit from the service of water conservation provided through the conservation of forests. Tourism companies should also pay for the direct benefits they receive through ecotourism and recreation activities in the reserve.

Third, there is a continuous challenge to improve the human well-being of local households (Yang et al., 2013b) with minimal interference to their local traditions and customs. The economic conditions of local households are still at a low level and many are still struggling to maintain basic livelihoods. Therefore, on the one hand, local households should be guided to find alternative income sources and increase their total income. Currently, agricultural income is the major economic source for most of the local households and is vulnerable to natural disasters (e.g., rainstorms, mountain torrents, landslides). The relatively small amount of subsidies received from various PES programs is not, neither now nor in the foreseeable future, the main income source for local households. But since the reserve is famous worldwide as the home to the endangered giant panda, it provides great opportunities to engage academic institutions, non-governmental organizations and industrial enterprises at different scales to meet local needs. For instance, current ecotourism and recreation activities in the reserve are largely directed by tourism development companies while local communities obtain few or no benefits (He et al., 2008; Liu et al., 2012). The spontaneously emerged "Happy Farmer's House" tourism and other potential solutions that are adaptive to local conditions (e.g., cultivation of traditional Chinese Medicine, ecocertified products, and multiple uses of forests, especially nontimber forest products) and that bring direct benefits to local households could also be important alternative solutions to consider (Liu et al., 2012). On the other hand, it is important to improve the quality of local elementary and high-school education (Liu et al., 1999a, 1999b, 2003b), the quality of local medical care, and social relations among households and between households and the local government (Yang et al., 2013b), all of which are essential components of human well-being (MA, 2005).

Finally, both short- and long-term socioeconomic effects related to the PES program and interaction effects among various policies (Liu et al., 2008) should be addressed. Whereas some studies in 
other areas (Daniels et al., 2010; Uchida et al., 2009) have discussed environmental and socioeconomic effects of PES programs, they are mostly scattered, fragmented, short term and opportunistic (Liu et al., 2008). In the reserve, although this study captured some short-term effects, many consequences are neither well-understood nor seriously tackled during the decision making processes. For instance, wildlife-induced losses (e.g., crop raids) are becoming a prevalent phenomenon throughout many protected areas in China due to the recovery of wildlife habitat and increase of wildlife population after the implementation of conservation policies (Cai et al., 2008; Liu et al., 2013; Zhang and Wang, 2003). However, to date, there are no policies or regulations to address such humanwildlife conflicts, since conservation needs mostly overwhelm personal and property rights in protected areas. It should be then emphasized that taking the socioeconomic effects related to the PES program into consideration is not only an ethical issue but also it is critical for the sustainability of current and future PES programs.

\section{Conclusions}

At the local scale, the PES program seems to have been responsible for most of the observed increase in forest cover in the reserve. Nevertheless, it had also induced some socioeconomic effects to local households such as impacts on local livelihoods, increasing wildlife-induced losses, and threats to local culture, traditions and customs. Many other short- and long-term effects as well as interaction effects with other conservation and development policies are largely unknown at this moment.

Lessons learned from this case study emphasize the importance of integrating local conditions as well as the need for understanding underlying mechanisms into the design and implementation of PES programs for their successful and sustainable performance. In the reserve, the successful performance of the NFCP included a combination of decentralization of forest monitoring activities to households, enforcement efforts, integration of PES with other auxiliary measures, and the emphasis on performance-based measures complementing command-and-control measures. Key issues regarding the effectiveness, efficiency, ethics, and sustainability of current and future PES programs include adaptation of the policy cycle, identification, selection and engagement of potential beneficiaries and benefactors, appropriate and effective incentive and punishment mechanisms, diversity and security of financial sources, alternative income sources for local residents, and solutions for short- and long-term negative socioeconomic effects.

Conservation policy planning and implementation are complex processes. Future interdisciplinary studies are needed to disentangle underlying complexities such as heterogeneity across space, time and PES targeting agents, complex interactions of driving forces, contextual effects, reciprocal effects and feedback loops between human and natural systems. As a global conservation hotspot, the Wolong Nature Reserve for giant pandas acts as a flagship both for China's and global conservation practice. Lessons learned in the Wolong Nature Reserve may also guide policy design and implementation in many other places across China and around the world.

\section{Acknowledgments}

We thank the Wolong Administrative Bureau for logistic help and particularly recognize the assistance from Jian Yang, Xiaogang Shi, Haibin Xu, Hao Tang, Mingchong Liu and Lun Wang. We gratefully acknowledge the financial support from the United States National Science Foundation (NSF: Dynamics of Coupled Natural and Human Systems program and Partnership for International Research and Education), the National Aeronautics and Space
Administration (NASA: Land Use/Land Cover Change program), and Michigan State University's Environmental Science and Policy Program, and Graduate Office.

\section{References}

Alix-Garcia, J., De Janvry, A., Sadoulet, E., 2008. The role of deforestation risk and calibrated compensation in designing payments for environmental services. Environ. Dev. Econ. 13, 375-394.

An, L., Liu, J., Ouyang, Z., Linderman, M., Zhou, S., Zhang, H., 2001. Simulating demographic and socioeconomic processes on household level and implications for giant panda habitats. Ecol. Model. 140, 31-49.

An, L., Lupi, F., Liu, J., Linderman, M.A., Huang, J., 2002. Modeling the choice to switch from fuelwood to electricity: implications for giant panda habitat conservation. Ecol. Econ. 42, 445-457.

An, L., Mertig, A.G., Liu, J., 2003. Adolescents leaving parental home: psychosocial correlates and implications for conservation. Popul. Environ. 24, 415-444.

Arriagada, R.A., Sills, E.O., Pattanayak, S.K., Ferraro, P.J., 2009. Combining qualitative and quantitative methods to evaluate participation in Costa Rica's Program of payments for environmental services. J. Sustain. Forest. 28, 343-367.

Bearer, S., Linderman, M., Huang, J.Y., An, L., He, G.M., Liu, J.Q., 2008. Effects of fuelwood collection and timber harvesting on giant panda habitat use. Biol. Conserv. 141, 385-393.

Cai, J., Jiang, Z.G., Zeng, Y., Li, C.W., Bravery, B.D., 2008. Factors affecting crop damage by wild boar and methods of mitigation in a giant panda reserve. Eur. J. Wildl. Res. 54, 723-728.

Chen, X., Lupi, F., He, G., Ouyang, Z., Liu, J., 2009. Factors affecting land reconversion plans following a payment for ecosystem service program. Biol. Conserv. 142, 1740-1747.

Chen, X., Lupi, F., Vina, A., He, G., Liu, J., 2010. Using cost-effective targeting to enhance the efficiency of conservation investments in payments for ecosystem services. Conserv. Biol. 24, 1469-1478.

Chen, X., Lupi, F., An, L., Sheely, R., Viña, A., Liu, J., 2012. Agent-based modeling of the effects of social norms on enrollment in payments for ecosystem services. Ecol Model. 229, 16-24.

Chhatre, A., Agrawal, A., 2008. Forest commons and local enforcement. Proc. Natl. Acad. Sci. U.S.A. 105, 13286-13291.

Daniels, A.E., Bagstad, K., Esposito, V., Moulaert, A., Rodriguez, C.M., 2010. Understanding the impacts of Costa Rica's PES: are we asking the right questions? Ecol. Econ. 69, 2116-2126.

FONAFIFO, CONAFOR, Ministry of Environment, 2012. Lessons Learned for REDD+ from PES and Conservation Incentive Programs. Examples from Costa Rica Mexico, and Ecuador. World Bank, Forest Trends and PROFOR, Costa Rica, Ecuador, Mexico. p. 164.

Gross-Camp, N.D., Martin, A., McGuire, S., Kebede, B., Munyarukaza, J., 2012. Payments for ecosystem services in an African protected area: exploring issues of legitimacy, fairness, equity and effectiveness. Oryx 46, 24-33.

Hardin, G., 1968. The tragedy of the commons. Science 162, 1243-1248.

He, G., Chen, X., Liu, W., Bearer, S., Zhou, S., Cheng, L., Zhang, H., Ouyang, Z., Liu, J., 2008 Distribution of economic benefits from ecotourism: a case study of Wolong Nature Reserve for Giant Pandas in China. Environ. Manage. 42, 1017-1025.

Jack, B.K., Kousky, C., Sims, K.R.E., 2008. Designing payments for ecosystem services: lessons from previous experience with incentive-based mechanisms. Proc. Natl. Acad. Sci. U.S.A. 105, 9465-9470.

Jensen, J.R., 1996. Introductory Digital Image Processing, a Remote Sensing Perspective, second ed. Prentice Hall, New Jersey.

Kalacska, M., Sanchez-Azofeifa, G.A., Rivard, B., Calvo-Alvarado, J.C., Quesada, M., 2008. Baseline assessment for environmental services payments from satellite imagery: a case study from Costa Rica and Mexico. J. Environ. Manage. 88, 348-359.

Liu, J., 2010. China's road to sustainability. Science 328, 974.

Liu, J., Diamond, J., 2005. China's environment in a globalizing world. Nature 435 1179-1186.

Liu, J., Ouyang, Z., Tan, Y., Yang, J., Zhou, S., 1999a. Changes in human population structure and implications for biodiversity conservation. Population and Environment $21,45-58$

Liu, J., Ouyang, Z., Taylor, W.W., Groop, R., Tan, Y., Zhang, H., 1999b. A framework for evaluating the effects of human factors on wildlife habitat: the case of giant pandas. Conserv. Biol. 13, 1360-1370.

Liu, J., Linderman, M., Ouyang, Z., An, L., Yang, J., Zhang, H., 2001. Ecological degradation in protected areas: the case of Wolong Nature Reserve for Giant Pandas. Science 292, 98-101.

Liu, J., Daily, G.C., Ehrlich, P.R., Luck, G.W., 2003a. Effects of household dynamics on resource consumption and biodiversity. Nature 421, 530-533.

Liu, J., Ouyang, Z., Pimm, S., Raven, P., Wang, X., Miao, H., Han, N., 2003b. Protecting China's biodiversity. Science 300, 1240-1241.

Liu, J., Li, S., Ouyang, Z., Tam, C., Chen, X., 2008. Ecological and socioeconomic effects of China's policies for ecosystem services. Proc. Natl. Acad. Sci. U.S.A. 105, 9477-9482.

Liu, W., Vogt, C.A., Luo, J., He, G., Frank, K.A., Liu, J., 2012. Drivers and socioeconomic impacts of tourism participation in protected areas. PLoS ONE 7, e35420.

Liu, J., Ouyang, Z., Yang, W., Xu, W., Li, S., 2013. Evaluation of ecosystem service policies from biophysical and social perspectives: the case of China. In: 
Levin, S.A. (Ed.), Encyclopedia of Biodiversity, second ed. Academic Press, Waltham, MA, pp. 372-384.

MA, 2005. Ecosystems \& Human Well-being: Synthesis (Millennium Ecosystem Assessment). Island Press, Washington, DC.

Olander, L.P., Gibbs, H.K., Steininger, M., Swenson, J.J., Murray, B.C., 2008. Reference scenarios for deforestation and forest degradation in support of REDD: a review of data and methods. Environ. Res. Lett. 3, 025011.

Ostrom, E., 1990. Governing the Commons: The Evolution of Institutions for Collective Action. Cambridge University Press, New York.

Ostrom, E., 2009. A general framework for analyzing sustainability of socialecological systems. Science 325, 419-422.

Ostrom, E., Gardner, R., Walke, J., 1994. Rules, Games, and Common-pool Resources. University of Michigan Press, Ann Arbor.

Ostrom, E., Burger, J., Field, C.B., Norgaard, R.B., Policansky, D., 1999. Revisiting the commons: local lessons, global challenges. Science 284, 278-282.

Ostrom, E., Janssen, M.A., Anderies, J.M., 2007. Going beyond panaceas. Proc. Natl. Acad. Sci. U.S.A. 104, 15176-15178.

Sanchez-Azofeifa, G.A., Pfaff, A., Robalino, J.A., Boomhower, J.P., 2007. Costa Rica's payment for environmental services program: intention, implementation, and impact. Conserv. Biol. 21, 1165-1173.

Schaller, G.B., Hu, J., Pan, W., Zhu, J., 1985. The Giant Pandas of Wolong. University of Chicago Press, Chicago.

Scherr, S.J., Bennett, M.T., Loughney, M., Canby, K., 2006. Developing Future Ecosystem Service Payments in China: Lessons Learned from International Experience. Forest Trends and PROFOR, Washington, DC.

Scullion, J., Thomas, C.W., Vogt, K.A., Perez-Maqueo, O., Logsdon, M.G., 2011. Evaluating the environmental impact of payments for ecosystem services in Coatepec (Mexico) using remote sensing and on-site interviews. Environ. Conserv. 38, 426-434.

State Forestry Administration of China, 2005. Report of Forest Resources in China. China Forestry Press, Beijing.

Task Force for Eco-Compensation Mechanisms and Polices in China, 2007. Ecocompensation Mechanisms and Polices in China. Science Press, Beijing.

Tuanmu, M.-N., 2012. Spatiotemporal Dynamics of Giant Panda Habitat: Implications for Panda Conservation under a Changing Environment. PhD Dissertation. Department of Fisheries and Wildlife. Michigan State University, East Lansing.

Uchida, E., Xu, J.T., Rozelle, S., 2005. Grain for green: cost-effectiveness and sustainability of China's conservation set-aside program. Land Econ. 81, 247-264.

Uchida, E., Rozelle, S., Xu, JT., 2009. Conservation payments, liquidity constraints, and off-farm labor: impact of the Grain-for-Green Program on rural households in China. Am. J. Agric. Econ. 91, 70-86.

Viña, A., Bearer, S., Chen, X., He, G., Linderman, M., An, L., Zhang, H., Ouyang, Z Liu, J., 2007. Temporal changes in giant panda habitat connectivity across boundaries of Wolong Nature Reserve, China. Ecol. Appl. 17, 1019-1030.

Viña, A., Bearer, S., Zhang, H., Ouyang, Z., Liu, J., 2008. Evaluating MODIS data for mapping wildlife habitat distribution. Remote Sens. Environ. 112, 2160-2169.
Viña, A., Chen, X., McConnell, W., Liu, W., Xu, W., Ouyang, Z., Zhang, H., Liu, J., 2011. Effects of natural disasters on conservation policies: the case of the 2008 Wenchuan Earthquake, China. Ambio 40, 274-284.

Viña, A., Chen, X., Yang, W., Liu, W., Li, Y., Ouyang, Z., Liu, J., 2013. Improving the efficiency of conservation policies with the use of surrogates derived from remotely sensed and ancillary data. Ecol. Indicat. 26, 103-111.

Wolong Nature Reserve, 2005. Development History of Wolong Nature Reserve [in Chinese]. Sichuan Science and Technology Press, Chengdu.

Wunder, S., 2005. Payments for Environmental Services: Some Nuts and Bolts. CIFOR Occasional Paper No. 42. Center for International Forestry Research, Bogor, Indonesia.

Wunder, S., 2007. The efficiency of payments for environmental services in tropical conservation. Conserv. Biol. 21, 48-58.

Wunder, S., Alban, M., 2008. Decentralized payments for environmental services: the cases of Pimampiro and PROFAFOR in Ecuador. Ecol. Econ. 65, 685-698.

Wunscher, T., Engel, S., Wunder, S., 2008. Spatial targeting of payments for environmental services: a tool for boosting conservation benefits. Ecol. Econ. 65 , $822-833$.

Xu, J.T., Katsigris, E., White, T.A., 2002. Implementing the Natural Forest Protection Program and the Sloping Lands Conversion Program. Western China Forests and Grassland Taskforce of China Council for International Cooperation on Environment and Development, Beijing.

Xu, J.T., Yin, R.S., Li, Z., Liu, C., 2004. Sloping land conversion: cost-effectiveness, structural adjustment, and economic sustainability. China Econ. Q. 4, 139-162 (in Chinese)

Yang, W., Chang, J., Xu, B., Peng, C., Ge, Y., 2008. Ecosystem service value assessment for constructed wetlands: a case study in Hangzhou, China. Ecol. Econ. $68,116-125$

Yang, W., Dietz, T., Ouyang, Z., Liu, J. Interaction effects of conservation and development policies on rural household income and income structure, submitted for publication.

Yang, W., Dietz, T., Liu, W., Luo, J., Liu, J., 2013a. Going beyond the Millennium Ecosystem Assessment: an index system of human dependence on ecosystem services. PLoS ONE 8, e64581. http://dx.doi.org/10.1371/journal.pone.0064581.

Yang, W., Dietz, T., Kramer, D.B., Chen, X., Liu, J., 2013b. Going beyond the Millennium Ecosystem Assessment: an index system of human well-being. PLoS ONE 8, e64582. http://dx.doi.org/10.1371/journal.pone.0064582.

Yang, W., Liu, W., Viña, A., Tuanmu, M., He, G., Dietz, T., Liu, J., 2013c. Nonlinear effects of group size on collective action and resource outcomes. Proc. Natl. Acad. Sci. U.S.A., http://dx.doi.org/10.1073/pnas.1301733110.

Yin, R.S., 2009. An Integrated Assessment of China's Ecological Restoration Programs. Springer, Dordrecht, The Netherlands.

Zhang, L., Wang, N., 2003. An initial study on habitat conservation of Asian elephant (Elephas maximus), with a focus on human elephant conflict in Simao, China. Biol. Conserv. 112, 453-459.

Zhang, H., Li, D., Wei, R., Tang, C., Tu, J., 1997. Advances in conservation and studies on reproductivity of giant pandas in Wolong. Sichuan J. Zool. 16, 31-33 (in Chinese). 